\title{
Mechanical Collision Simulation of Potato Tubers
}

\section{H. Kursat CELIK ${ }^{1, *}$, Recep CINAR ${ }^{2}$, Deniz YILMAZ ${ }^{3}$, Mihaela-Elena ULMEANU ${ }^{4}$, Allan E. W. RENNIE ${ }^{5}$, Ibrahim AKINCI ${ }^{1}$}

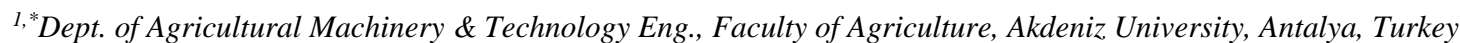 \\ ${ }^{2}$ Design and Engineering Bureau, Yenasoft Ltd., Istanbul, Turkey \\ ${ }^{3}$ Dept. of Agricultural Machinery \& Technology Eng., Faculty of Agricultural Sciences and Technologies, \\ Isparta University of Applied Sciences, Isparta, Turkey \\ ${ }^{4}$ Dept. of Manufacturing, University Politehnica of Bucharest, Bucharest, Romania \\ ${ }^{5}$ Lancaster Product Development Unit, Engineering Dept., Lancaster University, Lancaster, United Kingdom
}

$\begin{array}{ll}\text { Corresponding author } & : \text { Dr H. Kursat CELIK } \\ \text { e-mail } & : \text { hkcelik@akdeniz.edu.tr } \\ \text { Tel } & :+902423106570 \\ \text { Fax } & :+902422274564 \\ \text { Address } & : \text { Department of Agricultural Machinery \& Technology Engineering, } \\ & \text { Faculty of Agriculture, Akdeniz University, 07070, Antalya, Turkey }\end{array}$

\section{ABSTRACT}

This paper presents the results of an investigation on internal stress progression and the explicit dynamics simulation of the bruising behaviour of potato tubers under dynamic mechanical collision. Physical measurements, mechanical tests, advanced solid modelling and engineering simulation techniques were utilised in the study. The tuber samples used in the simulation were reverse engineered and finite element analysis (FEA) were set up to simulate the collision based bruising behaviour of the potato tubers. Total number of identical tuber models used in the simulation was 17 . The numerical data of the FEA results revealed useful stress distribution and mechanical behaviour visuals. These results are presented in a frame that can be used to describe bruise susceptibility value on potato-like agricultural crops. The modulus of elasticity was calculated from compression test data as 3.12 [MPa]. Structural stresses of $1.40[\mathrm{MPa}]$ and 3.13 [MPa] on the impacting (hitting) and impacted (hit) tubers (respectively) were obtained. These stress values indicate that bruising is likely to occur on the tubers. This research paper provides a useful how-to-do strategy to further research on complicated bruising investigations of solid-like agricultural products through advanced engineering simulation techniques.

KEYWORDS: Bruising simulation, finite element analysis, explicit dynamics, potato tuber, product collision

\section{PRACTICAL APPLICATIONS}

This research aims to simulate realistic dynamic deformation of potato tubers during mechanical collision which is very hard to achieve through physical or analytical expressions. This is attractive because related food processing industries have shown their interest in determining the physical properties and bruising behaviour of food/agricultural products using experimental, numerical and engineering simulation methods so that it can be used in their food processing technology. Very limited data have been found available in the literature about the subject of FEM based explicit dynamics simulation of solid-like agricultural crops such as the self-collision case of potato tubers (which is very important for indoor or outdoor potato processing). Comparative investigations on determination of modulus of elasticity are very limited as well. Most of the research, focused on single calculation theory and linear static loading assumption based FEM simulation solutions. Here we report a "how-to-do" case study for dynamic self-collision simulation of potato tubers. 


\section{INTRODUCTION}

Most of the damage on agricultural products is caused by mechanical collision, drop or crash/impact loadings that arise in the agricultural production stages such as harvesting, post-harvest and transportation. The food (vegetable and fruit) processing sectors experience commercial difficulties because of drop or crash/impact based mechanical damages to their products (García et al., 1995; Van Zeebroeck et al., 2003, 2007; Berardinelli et al., 2005; Gołacki et al., 2009, Prusky, 2011; Celik, 2011; Abedi and Ahmadi, 2013; Komarnicki et al., 2016; Celik, 2017a; Opara and Fadijia 2018). Specifically, Potato (Solanum tuberosum L.) is a globally important crop plant producing high yields of nutritionally valuable food in the form of tubers (Millam, 2006). The amount of total potato production worldwide is approximately 400 million ton per year and the most important potato producers are Chine, India, Russia, USA and Ukraine in the World. Turkey's production amount is 4.7 million in 2017 (ranked 16 $6^{\text {th }}$ in the world) (Abed, and Demirhan, 2018). In this important production chain, one of the major problems in the potato industry is impact bruising due to product collision (mechanical impact) in harvest, post-harvest and transportation operations, and mechanical impact based bruising is the common reason for a financial loss to the industry. Most especially, internal bruising is a refused circumstance because of its sneaky progress during storage time. Understanding and plotting the internal bruising that occurs upon mechanical loading in potato-like agricultural crops is a complicated problem. This is very difficult to explain because of the organic cellular structure of the agricultural/food materials and the accelerated bruising activity during the dynamic loading. This type of bruising may not be detected at first. Because, this is a kind of subcutaneous damage without skin fracture just after the dynamic impact loading (Mohsenin, 1986). The main reason for the product damage due to dynamic mechanical stress occurrence during impact loading should be precisely investigated in order to prevent such damage and losses in future. In fact, several experimental methods are available for determination of the product damage and mechanical stress magnitude that occurs during collision, however, as an efficient alternative solution, numerical methods based engineering simulation techniques can also be utilised (Pang et al., 1992a,b; Dintwa et al., 2008). Numerical method based simulation techniques are in use in wide range of engineering fields for nearly 70 years. These simulation techniques have also been highlighted as an effective and useful approximation techniques to complex engineering problems in agricultural engineering (such as mechanical impact based bruising cases of organic materials) (Sitkei, 1986).

Finite element analysis (FEA) is a successful analysis tool for developing approximate solutions to complex engineering problems and is very popular. These numerical method based simulations have been successfully applied to predict the behaviour of structures and specific product development systematics in various engineering disciplines (Khoei, 2015). Use of FEA technique can be seen specifically on agricultural/food product related studies in recently published scientific literatures (Celik, 2017a,b,c; Hoshyarmanesh et al., 2017; Li et al., 2017; Ji et al., 2017; Salarikia et al., 2017; Caglayan et al., 2018; Fadiji et al., 2018; Gao et al., 2018; Mahapatra and Tripathy, 2018; Ashtiani et al., 2019). These publications emphasise the advantages of the method in evaluation of the damage and bruising on the agricultural materials such as apples, pears, grapes etc. under various loading conditions. On the other hand, it is seen in these publications that not only static and linear assumptions but also dynamic and non-linearity are now available through new generation engineering analysis tools.

In reality, experimental evidence show that most of the organic (agricultural) products exhibit viscoelastic deformation pattern under physical loading cases (Mohsenin, 1986). Time-dependent and the viscoelastic bruising patterns, which are highly nonlinear, can be observed in real life impact cases of agricultural materials. In solution of this type of problems the explicit dynamics based engineering simulation approach may be highlighted as effective approach in solving bruising cases such as drop, crash/impact and self-collision phenomenon of various materials. The explicit dynamics approach is developed to simulate nonlinear structural mechanics applications in physics. In complex engineering problems, explicit 
methods can provide more relevant pathways and this may provide an alternative solution-finding progression (Wakabayashi et al., 2008; SolidWorks Doc. 2010; Lee, 2012; Wu and Gu, 2012; ANSYS Doc. 2016). Hence, the dynamic bruising of the potato tubers due to mechanical collisions may be described as dynamic structural mechanics problems to be solved by the explicit dynamics approach.

The aim of this work is to exhibit and to provide an understanding for the bruising characteristics and stress progression (time dependent) of potato tubers during dynamic collision cases through an explicit approach based non-linear numerical simulation. The material parameters of the tubers used in the FEA study were measured through physical compression tests and standard measurement techniques. The physical tubers were reverse engineered and FEA-based explicit dynamics simulation were set up to analyse the collision cases' bruising phenomenon for the potato tubers. Application procedures, which describe the how-to-do strategy highlighted in this paper, are presented in the following sections.

\section{MATERIALS AND METHODS}

\section{Physical Measurement \& Material Testing Procedures}

As a solid-like agricultural crop, the potato tubers present a comprehensible example for the reverse engineering and dynamic bruising simulation applications considered in this research. The tuber samples (agria kind) used in the experimental tests were randomly collected from a local supermarket in Antalya, Turkey. Density, poisson's ratio, modulus of elasticity and bio-yield stress values of the potato tubers are the essential material parameters which are required to simulate and evaluate the deformation/bruising by means of FEA. In order to determine some of these parameters (such as modulus of elasticity and bio yield stress point), an experimental test procedure was set up. Cylindrical specimens extracted from whole potato tubers (specimen dimensions: 20 x 25 [mm]) were tested through double plate material compression test device. The loading capacity of the compression test device was 2000 [N] (load sensor is ESIT load cell) and the data obtained from the tests were collected through an electronic data acquisition system. The biological material test laboratory of the Department of Agricultural Machinery and Technology Engineering (Akdeniz University, Antalya, Turkey) was employed for all physical measurements and mechanical tests of this study. All of the specimens were tested at a room temperature of $20^{\circ} \mathrm{C}$. The moisture content of the physical specimens were calculated after drying operation of the specimens $\left(24\right.$ hours at $\left.105^{\circ} \mathrm{C}\right)$. In fact, this method is based on water vaporising from a material to be analysed, and then the moisture content can be calculated on the basis of vaporised water mass loss $\left(M C=\left[\left(M_{1}-M_{2}\right) / M_{1}\right] \times 100\right.$; Where: $M C$ : Moisture content of the samples [\%]; $M_{1}$ : Weight of the samples before drying [g]. and $M_{2}$ : Weight of dry samples [g]) (Sitkei, 1986; Mohsenin, 1986; Zlatković1 and Rajković1, 2005; Elbatawi et al., 2008; Norell et al., 2016). A Nuve-FN 032/055/120 dry air steriliser was utilised for drying operation. The average moisture content of 10 specimens was calculated as 85.25 [\%] (wet-base). According to details given in the ASAE S368.4 W/Corr. 1 DEC2000 standard (R2012), a compression speed of 2.5-30 [mm· $\left.\mathrm{min}^{-1}\right]$ is suggested as the stated compression rate during the tests. Therefore an identical compression rate of $5\left[\mathrm{~mm} \cdot \mathrm{min}^{-1}\right]$ was set up for physical compression tests of the tuber specimens. 10 specimens were used for each of the tests. Physical measurements repeated three times on the tuber samples. During the tests, data acquisition sampling rate was set up as 10 [Hz]. The experimental set up and the graphics extracted from the compression test data, which represent the force-deformation behaviour of the potato specimens, can be seen in Figure 1.

( Figure 1. Experimental test set-up and graphical representation of the test data ) 


\section{D Solid Modelling Procedure}

To obtain realistic three-dimensional (3D) CAD data of the potato tubers, reverse engineering technology and advanced solid modelling techniques were utilised. The tuber samples were selected randomly from non-bruised test samples. The CAD model was multiplied in the simulation set up in order to prevent longer physical solving time in the simulation. The digitisation process of the potato tuber was carried out by a 3D laser scanner and the scanned product surfaces were described as point clouds. 3D scanning process was carried out through NextEngine-2020i 3D desktop laser scanner. Subsequently, scanned features were knitted and re-meshed into the Scan-StudioHD software. SolidWorks 3D parametric solid modelling software were employed for final surface refining of the tuber model. The digitisation process and essential geometrical features of the scanned tuber sample are shown in Figure 2.

\section{( Figure 2. Solid modelling of the potato tuber )}

\section{FEA set-up procedure}

Drop and impact test studies are focused on the consequence of the impact of a material with rigid/flexible platform or collision impact of the materials. Dropping a material on the planar rigid/flexible platform is a common application, hence the name. The drop height of the potato collision case was assumed as $0.50[\mathrm{~m}]$ and was simulated. In the collision scenario, a potato tuber was defined to free-fall onto other tubers from a predefined drop height under standard gravity. The velocity $(V)$ at impact was calculated from; $V=(2 \cdot g \cdot h)^{1 / 2}$, where $g$ is the gravitational constant $\left[\mathrm{m} \cdot \mathrm{s}^{-2}\right]$ and $h$ is the drop height $[\mathrm{m}]$. The software solves a dynamic problem as a function of time.

ANSYS Workbench explicit dynamics module was utilised to simulate the collision scenario. ANSYS Workbench is a commercial software environment for performing structural, thermal, and electromagnetic analyses and this environment is an intuitive up-front FEA tool that is used in conjunction with CAD systems. The potato models were assumed to be whole homogeneous flesh structures. Total number of identical tuber models used in the simulation was 17 . Frictionless contact definitions (nonlinear contact), standard earth gravity of $9.8066\left[\mathrm{~m} \cdot \mathrm{s}^{-2}\right]$ and an idealised material model (linear elasticity) for the tuber models were assumed for this collision scenario. An identical uniform meshing size was defined in processing mesh map of the tuber solid models. first impact moment, bruising, rebound in contact and total free-tocontact sequences after impact/collision energy absorption periods were essential decision making parameters in the collision event solve time. The capacity of the post-process solver was also taken into consideration for the physical computing time. In this regard, the collision event was solved for 0.01 [s]. A mobile workstation of Dell Precision M4800 Series (Intel Core ${ }^{\mathrm{TM}}$ i7-4910MQ CPU @ 2.90GHz, NVIDIA Quadro K2100M-2GB, and Physical Memory Total: 32 GB) was utilised as the solving platform. The FEA set up, meshing details and material parameters appointed in the FEA are given in Figure 3.

( Figure 3. The FEA set up, finite element model and material parameters )

\section{RESULTS AND DISCUSSION}

Physical test results for the potato specimens exhibited the force-deformation pattern of the tubers. Elasticity moduli and the bio-yield stress were obtained from the experiments as $3.12[\mathrm{MPa}]$ and $1.05[\mathrm{MPa}]$ respectively. Finney and Hall (1967), as the result of the compression test of Russet Rural tubers (cylindrical specimens), reported the mean value of elasticity moduli as 3.75 [MPa] (543 [psi]). Timbers et al. (1965) reported the elasticity moduli of the Netted Gem potatoes as 3.99 [MPa] (579 [psi]). It can be said that the findings for elastic moduli in this study are close to the elastic 
moduli values obtained by these research given above and, in a generalised perspective, these values can be considered as acceptably similar. The numerical difference between the values may be because of different kind of tubers and moisture content of the specimens used in the tests. The results obtained from the collision simulation revealed useful bruising visuals (stress distribution) with numerical data. Visually, the simulation results clearly exhibited bruising behaviour of the potato tubers and numerical outputs exhibited dynamic stress activity on the potato bodies during predescribed collision events. Figure 4 illustrates the stress sequence with a graphical representation for the collision case. This representation shows step by step progressing of the stress in time during collision case. The calculated stress in this representation is the equivalent stress which is known Von Mises stress. The von Mises stress is a criterion for yielding, widely used for ductile materials which is also known as Huber stress and is a measure that accounts for all six stress components of a general three-dimensional state of stress (Kurowski 2012). The simulation results revealed that there were nonlinear changes in stress magnitudes against time during collision. This is a very complicated event to represent through physical experiments. The maximum equivalent stress value (3.13 [MPa]) was obtained on the impacted (hit) tuber from the total collision simulation at 0.002 [s] (just after first contact). Maximum and minimum equivalent stress (Von-Mises) values on the impacting (hitting) tuber were $1.40[\mathrm{MPa}]$ and $0.128[\mathrm{MPa}]$ respectively at the simulation duration of $0.0048[\mathrm{~s}]$. These results revealed that impacting (hitting) and impacted (hit) potato tubers experienced bruising as the maximum stress values during the collision of the tubers were higher than the measured bio-yield stress threshold $(1.05[\mathrm{MPa}])$ of the potato tubers. This is a significant indicator in order to perceive and predict bruising susceptibility patterns of the potato tubers under dynamic collision conditions. Bruised volumes of the damaged tubers can also be extracted from the simulation results as the next step of this study.

\section{Figure 4. Simulation results}

\section{CONCLUSION}

The main purpose of this work was to exhibit the realistic bruising progression and mechanical stress distribution of potato tubers during dynamic collision event. To do this, physical measurements, experimental test data, reverse engineering technology and FEM based explicit dynamics simulation approach were utilised and dynamic stress sequence (dynamic bruising pattern) has been successfully exhibited. In this regard, the purpose of the study has been achieved. This study has also introduced a "how-to-do" simulation strategy for dynamic self-collision events. This strategy can also be adapted to different dynamic loading conditions experienced by potato-like agricultural crops. In addition to threedimensional time dependent stress and deformation progression visuals of the bruising behaviour, useful numerical data such as maximum stress and deformation magnitudes have also been successfully extracted from the FEA simulation. The numerical results indicated that potato tubers in collision experienced bruising under a pre-defined simulation scenario. In a specific manner, simulation print-outs revealed $3.13[\mathrm{MPa}]$ and $1.40[\mathrm{MPa}]$ stress values on the impacting (hitting) and impacted (hit) tubers respectively just after first contact. This was the clear bruising indicator for them according to the bio-yield stress point of the tubers. There is no doubt that the findings of this study can provide a deeper understanding for dynamic bruising sequence of potato tubers due to collisions which may be experienced in transportation, harvest/post-harvest and industrial product processing phases. This would also be helpful in the design of processes and mechanical systems used in fruit and vegetable processing industry. This study guides to further research on complicated bruising investigations of solid-like agricultural products through advanced engineering simulation techniques and related industrial agricultural product/food processing applications. 


\section{ACKNOWLEDGEMENTS}

This study is an originally prepared full text research which is the extended version of an abstract publication entitled "Determination of Time Dependent Stress Distribution on Potato Tubers at Mechanical Collision" which was presented in XIX. World Congress of the International Commission of Agriculture and Biosystems Engineering (CIGR) (22-25 April, 2018, Antalya, Turkey). Additionally, the authors wish to acknowledge that this study is partly supported financially by The Scientific Research Projects Coordination Unit of Akdeniz University (Turkey) and Lancaster Product Development Unit (LPDU) at Lancaster University (United Kingdom). 


\section{REFERENCES}

Abed, M.M. and Demirhan, B., (2018), A glance to potato plant (Solanum tuberosum L.) - (Patates bitkisine (Solanum tuberosum L.) genel bir bakiş. International Journal of Life Sciences and Biotechnology, 1(1): 1-9. (In Turkish).

Abedi, G. and Ahmadi, E., (2013). Design and evaluation a pendulum device to study postharvest mechanical damage in fruits: bruise modeling of red delicious apple. Australian Journal of Crop Science, 7: 962-968.

ANSYS Documentation, (2016). Release Notes: Explicit Dynamics Analysis. Release 17.1. ANSYS Inc..

ASAE S368.4 W/Corr. 1 DEC2000 (R2012). Compression test of food materials of convex shape. St. Joseph, MI: American Society of Agricultural Engineers (ASAE) Standards.

Ashtiani, S-H.M., Sadrnia, H., Mohammadinezhad, H., Aghkhani, M.H., Khojastehpour, M., Abbaspour-Fard, M.H., (2019), FEM-based simulation of the mechanical behavior of grapefruit under compressive loading, Scientia Horticulturae 245: 39-46.

Berardinelli, A., Donati, V., Giunchi, A., Guarnieri, A. and Ragni, L., (2005). Damage to pears caused by simulated transport. Journal of Food Engineering, 66: 219-226.

Caglayan, N., Oral, O., Celik, H.K., Cinar, R., Rodrigues, L.C. De A., Rennie, A.E.W., Akinci, I., (2018), Determination of time dependent stress distribution on a potato tuber during drop case. J Food Process Eng. 2018;41: e12869. https://doi.org/10.1111/jfpe.12869

Celik H.K., (2017a), Determination of bruise susceptibility of pears (Ankara Variety) to impact load by means of FEMbased explicit dynamics simulation. Postharvest Biology and Technology, 128: 83-97, DOI:10.1016/j.postharvbio.2017.01.015

Celik H.K., (2017b), Explicit dynamics simulation of Pecan fruit deformation under compressive loading-Part-1: Determination of modulus of elasticity. Journal of Food Process Engineering, e12581. https://doi.org/10.1111/jfpe.12581

Celik H.K., (2017c), Explicit dynamics simulation of Pecan fruit deformation under compressive loading-Part-2: Explicit dynamics simulation procedure. Journal of Food Process Engineering, e12582. https://doi.org/10.1111/jfpe.12582

Celik, H.K., Rennie, A.E.W., Akinci, I., (2011), Deformation behaviour simulation of an apple under drop case by Finite Element Method, Journal of Food Engineering (jfoodeng), Vol. 104: 293-298

Dintwa, E., Van Zeebroeck, M., Ramon, H., Tijskens, E., (2008), Finite element analysis of the dynamic collision of apple fruit, Postharvest Biology and Technology, 49 (2): 260-276

Elbatawi, I.E., Ebaid M.T., and Hemeda B. E., (2008), Determination of Potato Water Content using NIR Diffuse Reflection Method, Misr J. Ag. Eng., 25(4): 1279-1292.

Fadiji, T, Coetzee, C.J., Berry, T.M., Ambaw, A., Opara, U.L., (2018), The efficacy of finite element analysis (FEA) as a design tool for food packaging: A review, Biosystem Engineering, 174: 20-40.

Finney, E. E. and Hall, C. W., (1967). Elastic Properties of Potatoes, Transactions of the ASAE. 10 (1): 0004-0008. (DOI: $10.13031 / 2013.39578)$

Gao, Y., Song, C., Rao, X., Ying, Y., (2018), Image processing-aided FEA for monitoring dynamic response of potato tubers to impact loading, Computers and Electronics in Agriculture, 151: 21-30.

García, J., Ruiz-Altisent, M., and Barreiro, P., (1995). Factors influencing mechanical properties and bruise susceptibility of apples and pears. Journal of Agricultural Engineering Research, 61: 11-17.

Gołacki,K, Bobin,G., Stropek, Z., (2009), Bruise Resistance of Apples (Melrose Variety), TEKA Kom. Mot. Energ. Roln. - OL PAN, 9, 40-47.

Hoshyarmanesh, H., Dastgerdi, H.R., Ghodsi, M., Khandan, R., Zareinia, K., (2017), Numerical and experimental vibration analysis of olive tree for optimal mechanized harvesting efficiency and productivity, Computers and Electronics in Agriculture, 132: 34-48. 
Ji, W., Qian, Z., Xu, B., Tang, W., Li, J., Zhao, D., (2017), Grasping damage analysis of apple by end-effector in harvesting robot, J Food Process Eng. 2017;40:e12589

Khoei, A.R., (2015). Extended finite element method: Theory and APPLICATIONS. John Wiley \& Sons, UK ISBN: 978 $1-118-45768-9$.

Komarnicki, P., Stopa, R., Szyjewicz, D. and Młotek, M. (2016). Evaluation of bruise resistance of pears to impact load. Postharvest Biology and Technology, 114: 36-44.

Kurowski, P., (2012), Engineering analysis with Solidworks simulation 2012, SDC Publications, ISBN: 9781585037100, pp. 475.

Lee, H.-H., (2012). Finite element simulation with ANSYS Workbench 14. SDC Publications, pp. 608 ISBN: 978 1585037254.

Li, Z., Andrews, J., Wang, Y., (2017), Mathematical modelling of mechanical damage to tomato fruits, Postharvest Biology and Technology, 126: 50-56.

Mahapatra, A. and Tripathy, P.P., (2018), Modeling and simulation of moisture transfer during solar drying of carrot slices, J Food Process Eng. 2018; 41:e12909.

Millam, S., (2006), Potato (Solanum tuberosum L.). Agrobacterium Protocols Volume 2, 25-35. DOI:10.1385/1-59745131-2:25

Mohsenin, N.N., (1986). Physical properties of plant and animal materials, 2nd ed. Gordon and Breach Science Publishers, New York, pp. 891.

Norell, R. J., Glaze, Jr., J.B., Chahine, M. and Olsen N., (2016), Measuring potato dry matter content on the farm, CIS-1219: The University of Idaho Extension Publications and Multimedia, Available URL: httpswww.cals.uidaho.eduedcommpdfCISCIS1219.pdf, [Last Accessed: 23.01.2019].

Opara, U.,L., Fadijia, T. (2018). Compression damage susceptibility of apple fruit packed inside ventilated corrugated paperboard package, Scientia Horticulturae, 227,154-161.

Pang, W., Studman, C. J., Ward, G. T., (1992a). Bruising damage in apple-to-apple impact. Journal of Agricultural Engineering Research, 52, 229-240.

Pang, W., Studman, C.J., Banks, N.H., (1992b) Analysis of damage thresholds in apple-to-apple impacts using an instrumented sphere, New Zealand Journal of Crop and Horticultural Science, 20(2): 159-166.

Prusky, D., (2011). Reduction of the incidence of postharvest quality losses, and future prospects. Food Secur. 3, $463-474$.

Salarikia, A., Ashtiani, S-H.M., Golzarian, M.R., Mohammadinezhad, H., (2017), Finite element analysis of the dynamic behavior of pear under impact loading, Information Processing In Agriculture 4: 64-77.

Sitkei, G., (1986). Mechanics of Agricultural Materials. Elsevier Science Publisher, Hungary, ISBN: 0-444-99523-3

SolidWorks Documentation, (2010). SolidWorks Simulation Premium: Nonlinear. Training Manual Serial No: 22658021044 ENG0001. Dassault Systemes SolidWorks Corporation, USA.

Timbers, G. E., Staley, L, M., and Watson, E. L., (1965). Determining modulus of elasticity in agricultural products by loaded plungers. Agricultural Engineering 46: (5) 274-275.

Van Zeebroeck M., Van linden, V., Ramon, H., De Baerdemaeker, J., Nicolaï, B. and Tijskens, E., (2007). Impact damage of apples during transport and handling. Postharvest Biology and Technology, 45: 157-167.

Van Zeebroeck, M., Tijskens, E., Liedekerke, P., Deli, V., (2003). Determination of the dynamical behaviour of biological materials during impact using a pendulum device. Journal of Sound and Vibration, 266: 465-480.

Wakabayashi, N., Ona, M., Suzuki, T., Igarashi, Y., (2008). Nonlinear finite element analyses: advances and challenges in dental applications. J. Dent. 36, 463-471.

Wu, S.R., Gu, L., (2012). Introduction to the explicit finite element method for nonlinear transient dynamics. Wiley Publication ISBN: 9780470572375 , pp. 352.

Zlatković1 B.P. and Rajković1 M.B., (2005), Analysis of drying potato kinetics in laboratory conditions, Journal of Agricultural Sciences, 50(2): 161-171. 


\section{Figure Captions}

Figure 1. Experimental test set-up and graphical representation of the test data

Figure 2. Solid modelling of the potato tuber

Figure 3. The FEA set up, finite element model and material parameters

Figure 4. Simulation results 


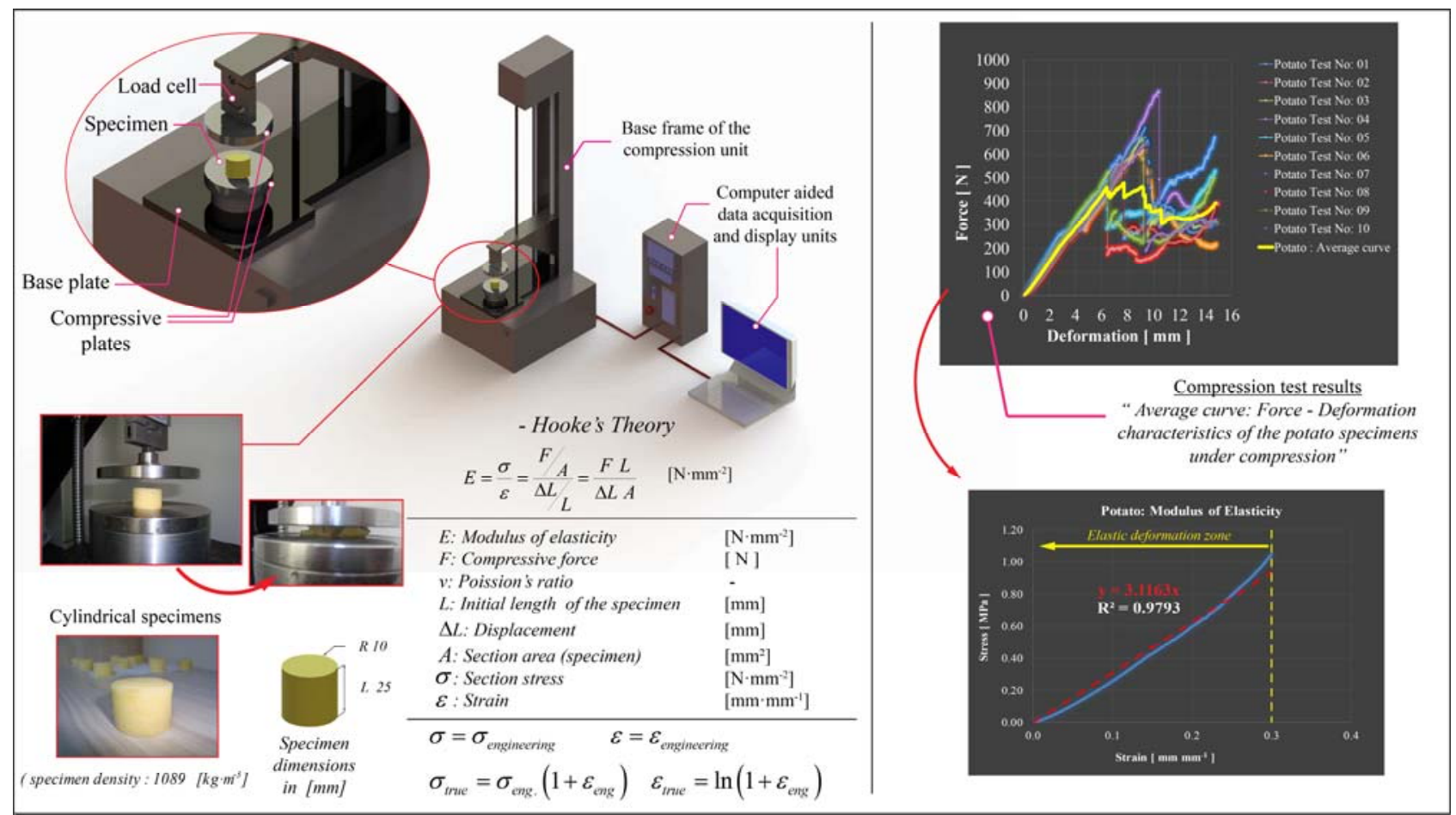

Figure 1. Experimental test set-up and graphical representation of the test data 


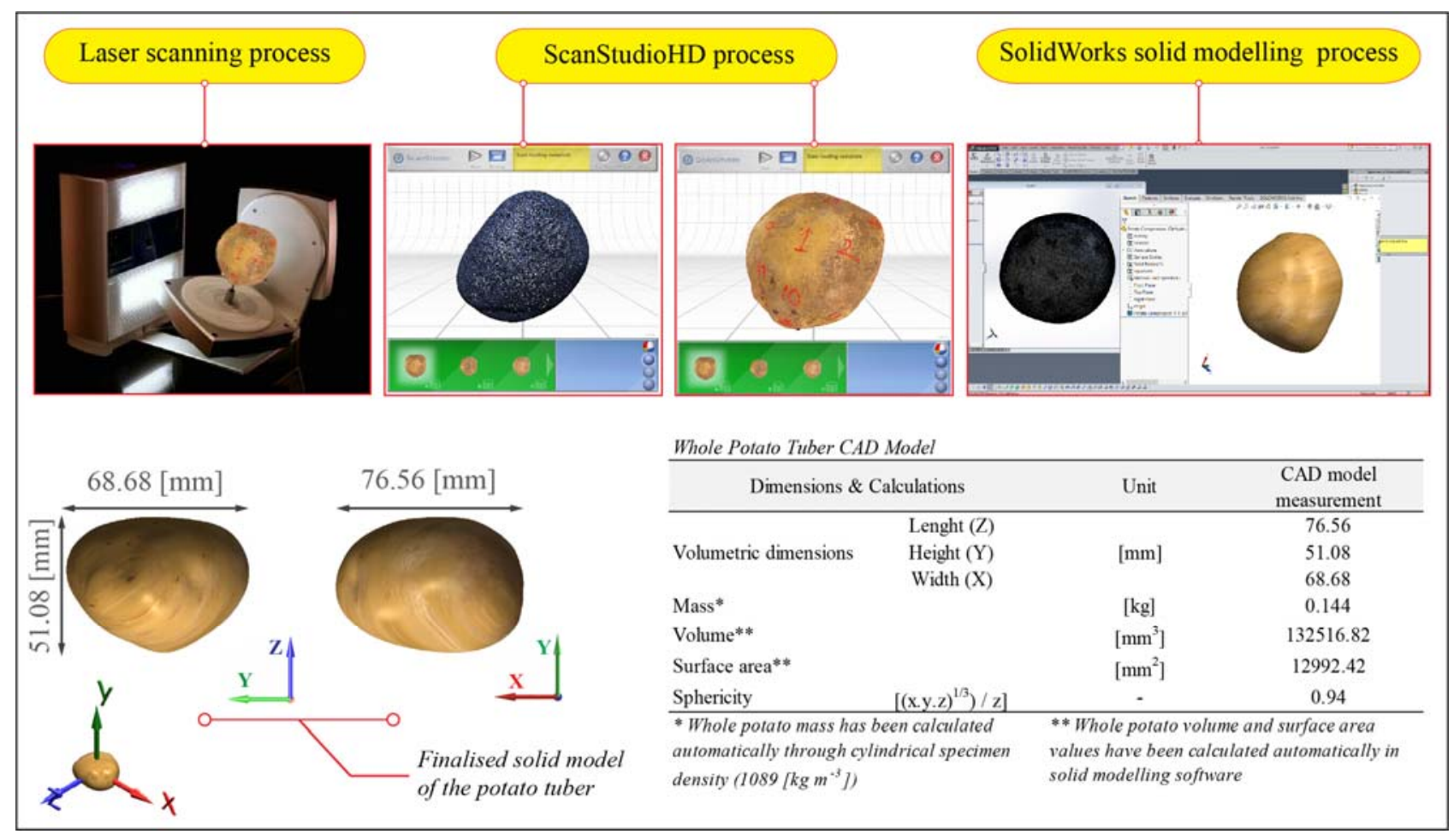

Figure 2. Solid modelling of the potato tuber 


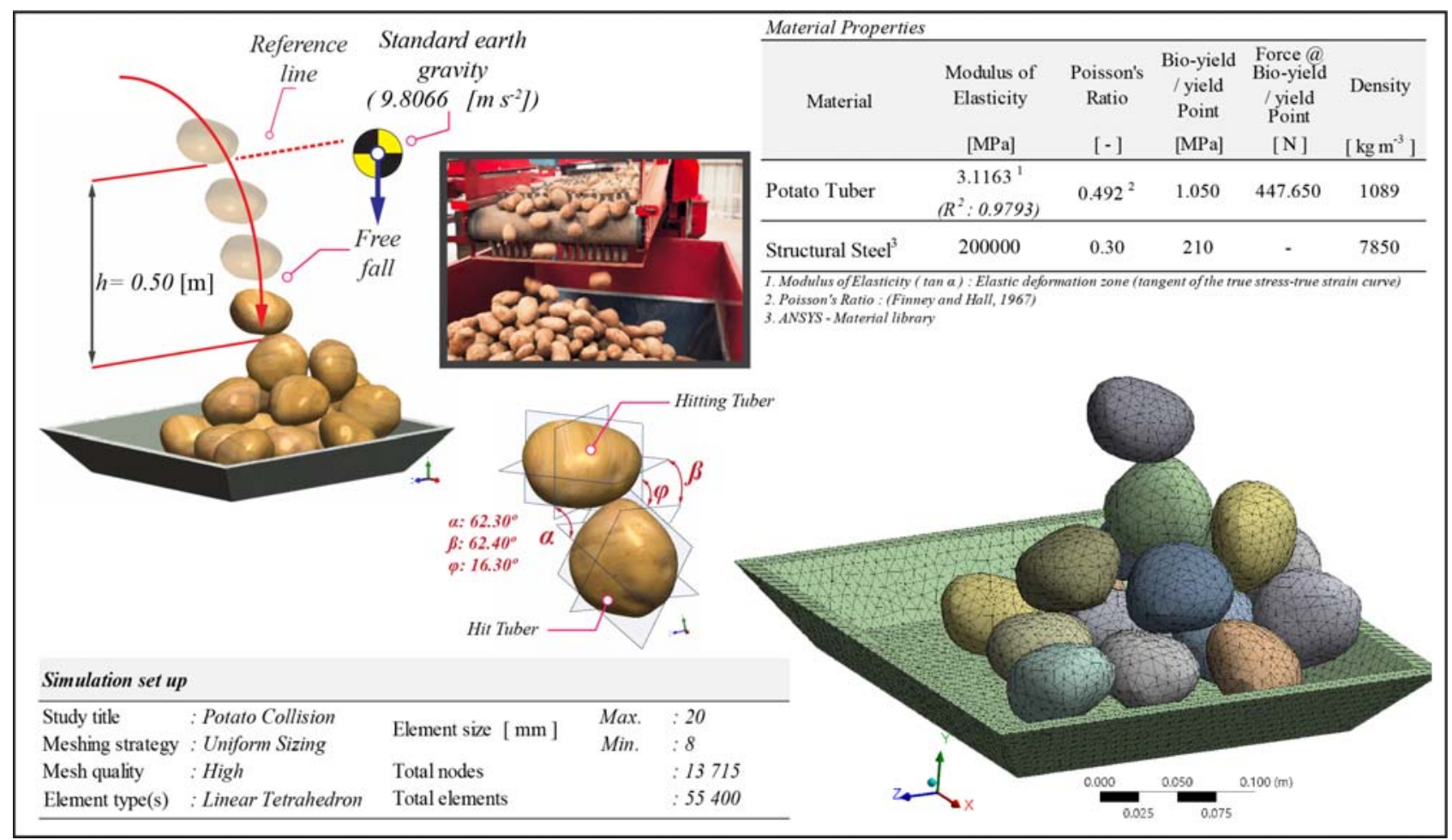

Figure 3. The FEA set up, finite element model and material parameters 


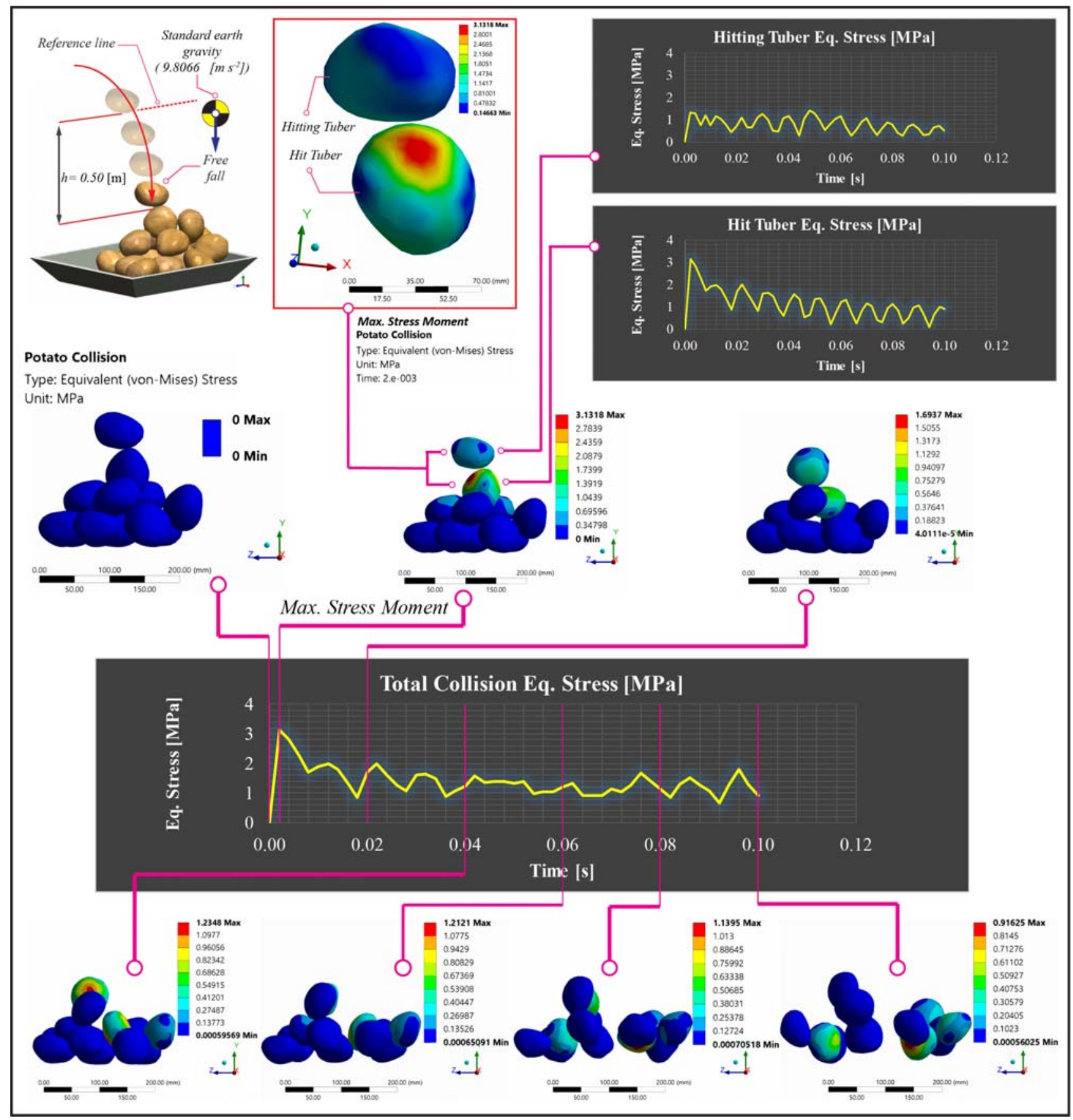

Figure 4. Simulation results 